\title{
Shear Strength of Trapezoidal Corrugated Steel Webs
}

\author{
Li Zhu ${ }^{1, a^{*}}$ and Wenyu $\mathrm{Ji}^{2, \mathrm{~b}}$ \\ ${ }^{1}$ School of Civil Engineering, Beijing Jiaotong University, Beijing, China \\ ${ }^{2}$ School of Civil Engineering, Beijing Jiaotong University, Beijing, China \\ azhuli@bjtu.edu.cn, bwyji@bjtu.edu.cn
}

\begin{abstract}
Keywords: Trapezoidal corrugated steel webs; Elastic shear buckling strength; Shear strength; Initial geometric imperfection; Prediction formula

Abstract. Shear strength of trapezoidal corrugated steel webs is an important issue for the design of box girder bridges with trapezoidal corrugated steel webs. In this study, a shell element FE model of trapezoidal corrugated steel webs is firstly built for the further analysis of shear behavior. Extensive parametric studies based on the linear elastic buckling analysis are then conducted to propose an appropriate formula for calculating the elastic shear buckling strength. Furthermore, the nonlinear buckling analysis is conducted to intensively investigate the shear strength associated with initial geometric imperfections, and the formulae of the shear strength are proposed. Good agreements can be observed between the results calculated using the proposed prediction formula and the experimental results.
\end{abstract}

\section{Introduction}

Trapezoidal corrugated steel webs used in the box girder can provide enhanced shear buckling strength in comparison with plane steel webs so that the stiffeners can be saved and the steel consumption can be reduced. For box girders with trapezoidal corrugated steel webs, due to the accordion effect, the bending moment can be assumed to be carried entirely by the concrete flanges and the webs only carry almost the entire shear with a uniform stress distribution over the web height. Thus, the shear strength can be determined without the consideration of moment-shear interaction, and the shear strength of trapezoidal corrugated steel webs may significantly influence the ultimate shear loading capacity of the whole box girder. Researches on the shear behavior of $\mathrm{H}$-shape steel girders with trapezoidal corrugated webs were initiated by Easley and McFarLand in 1969 [1]. Since then, experimental and theoretical researches on the shear buckling characteristics and the shear strength of trapezoidal corrugated steel webs have been conducted by Linder and Aschinger [2], Elgaaly et al. [3], Say-Ahmed [4], Driver et al. [5], Yi et al. [6] and Moon et al. [7], Sause and Braxtan [8]. Based on their valuable contributions, the analytical solutions for the elastic local and global shear buckling strengths have been deduced, and some formulae for predicting the shear strength have also been proposed. However, the influence of initial imperfections on the shear strength of trapezoidal corrugated steel webs has not been fully addressed, and a mature and widely applicable design method for the prediction of the shear strength is still lacking.

In this paper, a shell element FE model of trapezoidal corrugated steel webs is firstly built. Secondly, the linear elastic and nonlinear buckling analysis are conducted to derive the elastic shear buckling strength and the normalized shear strength -shear buckling slenderness ratio selationship, respectively. Finally, the proposed formula of shear strength is verified by the experimental results.

\section{Finite Element Model}

Previous numerical studies typically use the model of girder with flanges and stiffeners to investigate the shear behavior of webs[9-12]. However, it is usually difficult to make clear how a pure trapezoidal corrugated steel web behaves under shear when such a numerical model is used. Thus, in this paper, only a pure trapezoidal corrugated steel web is modeled, and flanges and stiffeners are replaced with simple support boundary condition for the conservative consideration. Fig. 1 shows a 
finite element model of the trapezoidal corrugated steel web based on the general FE program ANSYS 13.0. In this model, the out-of-plane freedoms of all the edge nodes are constrained as shown in Fig. 1a, and the AC and BD edges are at the center line of the corrugated web profile as shown in Fig. 1b. The load is applied along the CD edge to make the web under a pure shear state. The trapezoidal corrugated steel web is simulated using the SHELL181 elemen. Elastic modulus $E$ and Poisson ratio of steel material are $2.06 \times 10^{5} \mathrm{MPa}$ and 0.3 , respectively. This model can be used for the further analyses on linear and nonlinear buckling behaivors of trapezoidal corrugated steel webs.

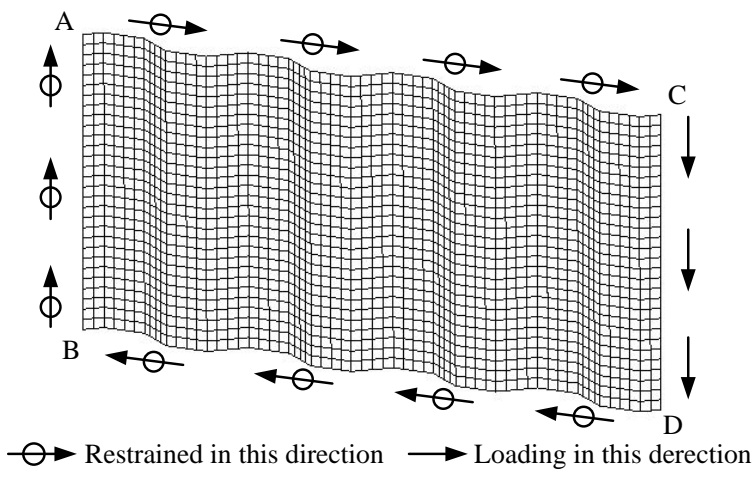

(a) Mesh and boundary condition

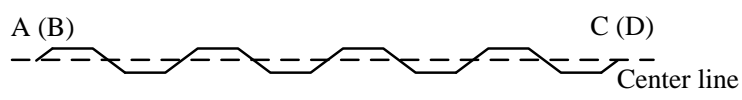

(b) Position of AC (BD) edge

Fig. 1 Finite element model

\section{Elastic Shear Buckling Strength}

\section{Classical theory}

Fig. 2 gives the geometric notations of trapezoidal corrugated steel webs. Generally, the shear buckling modes of trapezoidal corrugated steel webs include local shear buckling, global shear buckling and interactive shear buckling. Local shear buckling involves a single flat panel, whereas global shear buckling involves multiple panels with buckles extending diagonally over the entire web height. Interactive shear buckling, which involves a few panels, occurs due to the interaction of local and global shear buckling. The elastic local and global shear buckling strength ${ }_{\mathrm{L}, \mathrm{el}}$ and ${ }_{\mathrm{G}, \mathrm{el}}$ can be calculated using Eqs. (1) and (2) ${ }^{[1,13]}$, respectively, based on the classical elastic theory:

$$
\begin{gathered}
\tau_{\mathrm{L}, \mathrm{el}}=k_{\mathrm{L}} \frac{\pi^{2} E}{12\left(1-v^{2}\right)(w / t)^{2}} \\
\tau_{\mathrm{G}, \mathrm{el}}=k_{\mathrm{G}} \frac{E t^{1 / 2} h_{\mathrm{r}}^{3 / 2}}{12 h^{2}}\left(\frac{b+d}{b+c}\right)^{1 / 4}\left(\frac{3 b+c}{b+d}\right)^{3 / 4}
\end{gathered}
$$

where $w=$ maximum fold width (maximum value of the longitudinal fold width $b$ and the inclined foldwidth $c$ ); $k_{\mathrm{L}}$ is the local shear buckling coefficient, which can be calculated as Eqs. (3) and (4) for the simple and fixed supports, respectively ${ }^{[13]} ; k_{\mathrm{G}}$ is the global shear buckling coefficient, which can be calculated as Eqs. (5) and (6) for the simple and fixed supports, respectively ${ }^{[14]}$.

$$
\begin{gathered}
k_{\mathrm{L}, \mathrm{s}}=5.34+4.0(h / w)^{2} \\
k_{\mathrm{L}, \mathrm{f}}=8.98+5.6(h / w)^{2} \\
k_{\mathrm{G}, \mathrm{s}}=1.2747(h / a)^{2}+0.7603(h / a)+34.176 \\
k_{\mathrm{G}, \mathrm{f}}=3.0545(h / a)^{2}-0.0231(h / a)+64.195
\end{gathered}
$$




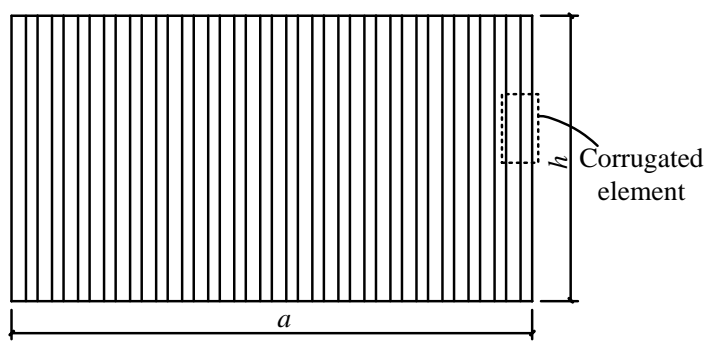

(a) Overall dimension

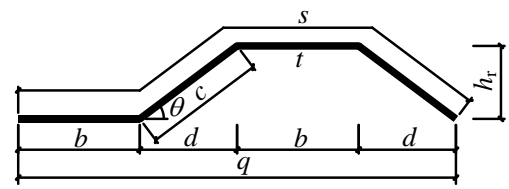

(b) Corrugated configuration

Fig. 2 Geometrical notations

The interactive shear buckling mode has the characteristics of both the local and global shear buckling modes, so the elastic interactive shear buckling strength ${ }_{\mathrm{I}, \mathrm{el}}$ is closely related with both $\mathrm{L}$,el and $\mathrm{G}_{\mathrm{Gel}}$. The prediction formula form as Eq. (7) proposed by some researchers ${ }^{[6,15-17]}$ is basically employed to predict the elastic interactive shear buckling strength $\tau_{\mathrm{I}, \mathrm{el}}$.

$$
\left(\frac{\tau_{\mathrm{I}, \mathrm{el}}}{\tau_{\mathrm{G}, \mathrm{el}}}\right)^{n}+\left(\frac{\tau_{\mathrm{I}, \mathrm{el}}}{\tau_{\mathrm{L}, \mathrm{el}}}\right)^{n}=1
$$

The relationship between $\mathrm{I}_{\mathrm{I}, \mathrm{l}}-\mathrm{G}_{\text {,el }}$ and $\mathrm{I}_{\mathrm{I}, \mathrm{el}}-\mathrm{L}_{\mathrm{el}}$ with the change of $n$ according to Eq. (7) is shown in Fig. 3. The shape of curves tends to be more concave with the decreasing of $n$, indicating more conservative predictions of ${ }_{\mathrm{I}, \mathrm{e}}$.

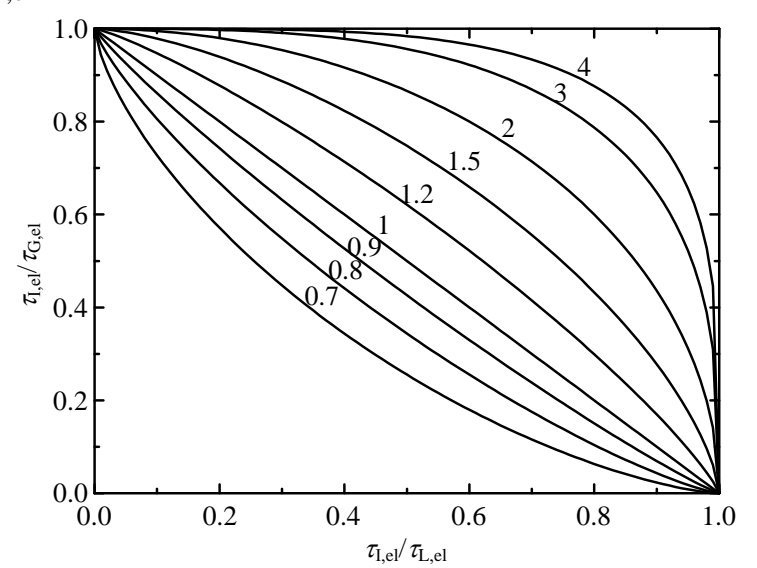

Fig. $3_{\mathrm{I}, \mathrm{el}} / \mathrm{G}_{\mathrm{G}, \mathrm{e}}^{-} \mathrm{I}, \mathrm{el} / \mathrm{L}, \mathrm{el}$ relationship according to Eq. (7)

\section{Suggested formula}

From Eqs. (1) and (2), the ratio of ${ }_{\mathrm{G}, \mathrm{el}}$ to $\mathrm{L}, \mathrm{el}_{\mathrm{l}}$ can be expressed as

$$
\frac{\tau_{\mathrm{G}, \mathrm{el}}}{\tau_{\mathrm{L}, \mathrm{el}}}=\left(\frac{1-v^{2}}{\pi^{2}}\right) \frac{k_{\mathrm{G}}}{k_{\mathrm{L}}} \frac{(3 b+c)^{3 / 4}}{(b+d)^{1 / 2}(b+c)^{1 / 4}}\left(\frac{w}{h}\right)^{2}\left(\frac{h_{\mathrm{r}}}{t}\right)^{3 / 2}
$$

$b / c$ value of 1.0 selected in the usual actual bridge girders is assumed. Thus, from Eq. (8), it can be found that the ratio of $\mathrm{G}_{\mathrm{Gel}}$ to $\mathrm{L,el}$ is mainly affected by the geometric parameters $b / h$ and $h_{\mathrm{r}} / t$. According to Ref. ${ }^{[6]}, b / h$ varies from 0.1 to 0.2 and $h_{\mathrm{r}} / t$ varies from 10 to 25 in the usual actual bridge girders. In this paper, $b / h$ and $h_{\mathrm{r}} / t$ are conservatively assumed to be in the range of $0.1 \sim 0.3$ and $6 \sim 30$, respectively, while other geometric parameters hold fixed as $t=10 \mathrm{~mm}, \theta=37^{\circ}$ and $a=4 q$. For each $h_{\mathrm{r}} / t, b / h$ varies from 0.10 to 0.30 at the increment of 0.01 , and for each $b / h, h_{\mathrm{r}} / t$ varies from 6 to 30 at the increment of

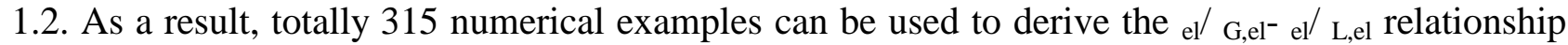
through the linear elastic buckling analysis as shown in Fig. 4, where el is the elastic shear buckling strength of trapezoidal corrugated steel webs. 


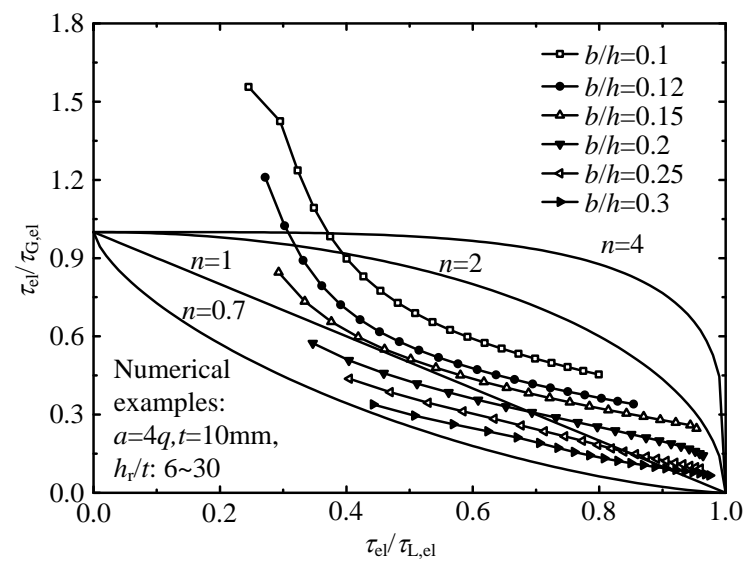

(a) $h_{\mathrm{r}} / t$ varies for different values of $b / h$

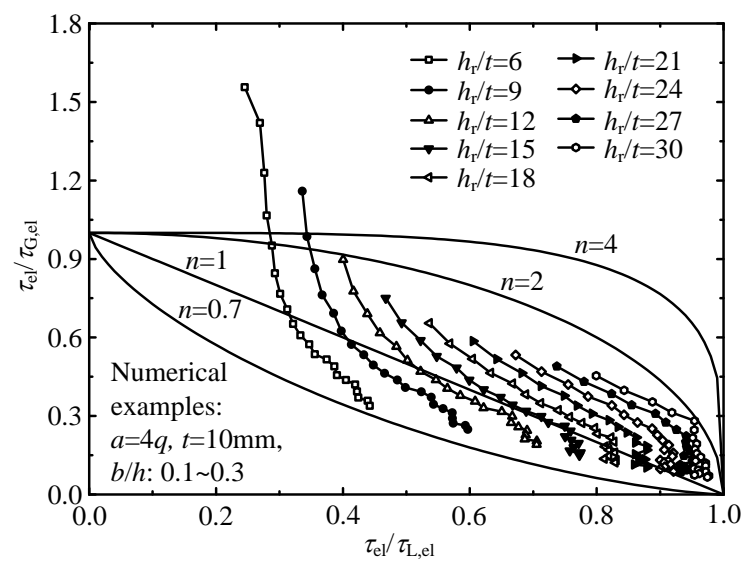

(b) $b / h$ varies for different values of $h_{\mathrm{r}} / t$

Fig. 4 Numerical results of el $/ \mathrm{G}, \mathrm{el}^{-}$el $/ \mathrm{L}$,el relationship

It can be observed from Fig. 4 that $(1)_{\mathrm{el}} / \mathrm{G}_{\mathrm{ee}} \mathrm{e}^{-} \mathrm{el} / \mathrm{L}$,el relationship shows the similar characteristic for different values of $b / h$ and different values of $h_{\mathrm{r}} / t ;(2)_{\mathrm{el}}$ is large than $\mathrm{G}_{\mathrm{G}, \mathrm{el}}$ with the upper limit of $1.5_{\mathrm{G}, \mathrm{el}}$ when $_{\mathrm{L}, \mathrm{el}}$ is much larger than $\mathrm{G}_{\mathrm{eel}}$, whereas el is smaller than $_{\mathrm{L}, \mathrm{el}}$ with the upper limit of ${ }_{\mathrm{L}, \mathrm{el}}$ when ${ }_{\mathrm{L}, \mathrm{el}}$ is much smaller than $_{\mathrm{G}, \mathrm{el}}$; (3) the elastic interactive shear buckling strength ${ }_{\mathrm{I}, \mathrm{el}}$ calculated using Eq. (7) with the $n$ value of 0.7 gives the lower bound prediction of the elastic shear buckling strength el considering three different shear buckling modes; and (4) I,el calculated using Eq. (7) with the $n$ value of 1 may give an appropriate prediction of the elastic shear buckling strength el compared to those formulae from other $n$ values. Therefore, Eq. (9) is adopted to calculate the elastic shear buckling strength considering three different shear buckling modes.

$$
\tau_{\mathrm{el}} \approx \tau_{\mathrm{I}, \mathrm{el}}=\frac{\tau_{\mathrm{L}, \mathrm{el}} \cdot \tau_{\mathrm{G}, \mathrm{el}}}{\tau_{\mathrm{L}, \mathrm{el}}+\tau_{\mathrm{G}, \mathrm{el}}}
$$

\section{Formulae for shear strength}

Shear strength of trapezoidal corrugated steel webs is usually evaluated based on the relationship of the normalized shear strength and the shear buckling slenderness ratio ${ }_{s}{ }^{[5-8]}$. The normalized shear strength and the shear buckling slenderness ratio ${ }_{s}$ are defined following two equations, respectively:

$$
\begin{gathered}
\rho=\frac{\tau_{\text {cr }}}{\tau_{\mathrm{y}}} \\
\lambda_{\mathrm{s}}=\sqrt{\frac{\tau_{\mathrm{y}}}{\tau_{\mathrm{el}}}}
\end{gathered}
$$

where $_{\mathrm{cr}}$ is the shear strength, and $\mathrm{y}_{\mathrm{y}}$ is the shear yield strength determined using the von Mises yield criterion as

$$
\tau_{\mathrm{y}}=\frac{f_{\mathrm{y}}}{\sqrt{3}}
$$

where $f_{\mathrm{y}}$ is the uniaxial yield strength of the steel material.

\section{Influence of initial geometric imperfections}

This subsection analyzes the influence of initial geometric imperfections on shear strength of trapezoidal corrugated steel webs by using FE analysis. The distribution of the initial geometric imperfections at the web is approximately assumed as the first elastic shear buckling mode obtained from the linear elastic buckling analysis. A perfect elasto-plastic model is chosen to define the uniaxial stress-strain relationship of the steel material and the von Mises yield criterion is employed.

The shear strength of trapezoidal corrugated steel webs is closely related to both the shear buckling strength and the shear yield strength, so two different cases should be considered: (1) the shear buckling strength is smaller than the shear yield strength; and (2) the shear buckling strength is larger 
than the shear yield strength. Corrugated configurations as shown in Table 1 are adopted in the numerical examples while other geometric characteristics are selected as $a=h=20 q$ for case (1) and $a=h=8 q$ for case (2). The uniaxial yield strength $f_{\mathrm{y}}$ of the steel material is selected as $235 \mathrm{MPa}$. Fig. 5 shows load versus displacement responses obtained from the nonlinear buckling analysis for these two cases.

Table 1 Dimension of trapezoidal corrugated sections

\begin{tabular}{ccccccc}
\hline$b(\mathrm{~mm})$ & $d(\mathrm{~mm})$ & $\left(^{\circ}\right)$ & $h_{\mathrm{r}}(\mathrm{mm})$ & $s(\mathrm{~mm})$ & $q(\mathrm{~mm})$ & $t(\mathrm{~mm})$ \\
\hline 20 & 16 & 37 & 12 & 80 & 72 & 1.00 \\
\hline
\end{tabular}

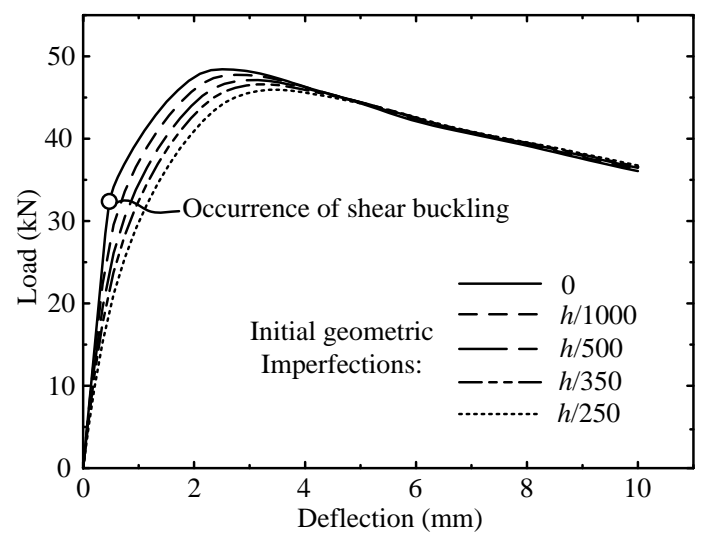

(a) Shear buckling strength is smaller than shear yield strength

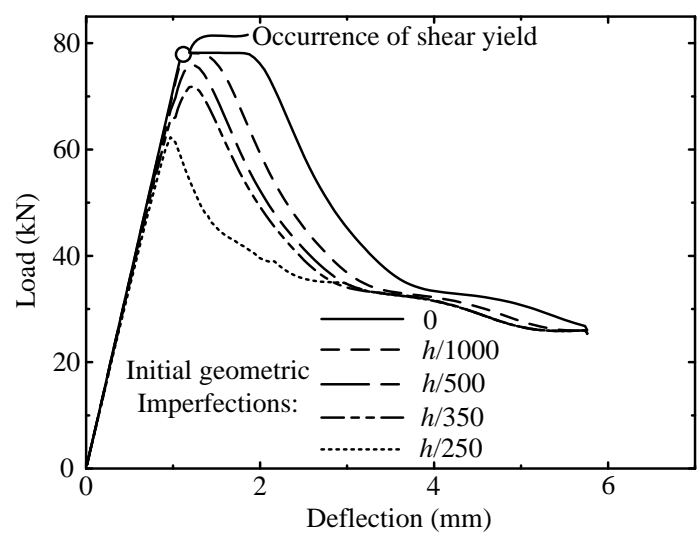

(b) Shear buckling strength is larger than shear yield strength

Fig. 5 Load versus deflection responses for case (1) and (2)

It can be observed from Fig. 5a for case (1) that the membrane effect of the web is fully developed due to the stable boundary condition so that the shear loading capacity can still increase continuously after the shear buckling strength of webs is achieved. The ultimate loading capacity decreases with the increasing of initial geometric imperfections, whereas the loading capacity of webs at the descending stage is almost independent of the initial geometric imperfections. The reason is that the early occurrence of the web out-of-plane deformation due to the shear buckling before the shear yield can reduce the sensitivity of the loading capacity at the descending stage to the initial geometric imperfections. On the contrary, initial geometric imperfections have obvious reduction effect on the loading capacity at the descending stage for case (2) in which the shear buckling occurs after the shear yield as shown in Fig. $5 \mathrm{~b}$ due to the later occurrence of the shear buckling and the smaller web out of plane deformation at the descending stage than those of case (1). In addition, the gradually developed membrane effect within the whole loading procedure is observed to play a certain role to increase the web shear strength.

\section{Proposed formula}

Limited test data are available for the actual initial geometric imperfections of $\mathrm{H}$-shape steel girders with trapezoidal corrugated webs and the influence of initial geometric imperfections on the shear strength of webs. The numerical method is a powerful tool to intensively investigate the shear strength associated with initial geometric imperfections and to finally derive the formulae of the $-\mathrm{s}$ relationship.

The corrugated configuration $q$ and shear span ratio $a / h$ are the two key characteristic parameters of H-shape girders with trapezoidal corrugated steel webs. In order to investigate the influence of these two parameters on the shear behavior of the trapezoidal corrugated steel webs with initial geometric imperfections, two groups of numerical examples are designed, and the corresponding results with the assumed initial geometric imperfection of $h / 250$ can be seen as Fig. $6 \mathrm{a}$ and $\mathrm{b}$, respectively.

For the first group of the numerical examples, the corrugated configuration $q$ changes when the shear span ratio $a / h$ is kept constant, and the detailed values of all the parameters are listed as follows:

$\cdot b=c=20 \mathrm{~mm},=37^{\circ}, t=1 \mathrm{~mm}, a=2 h=2 q \sim 50 q$ (totally 49 models) 
- $b=c=70 \mathrm{~mm},=37^{\circ}, t=2 \mathrm{~mm}, a=2 h=2 q \sim 37 q$ (totally 36 models)

- $b=c=250 \mathrm{~mm},=37^{\circ}, t=8 \mathrm{~mm}, a=2 h=2 q \sim 43 q$ (totally 42 models).

For the second group of the numerical examples, the shear span ratio a/h changes when the corrugated configuration $q$ is kept constant, and the detailed values of all the parameters are listed as follows:

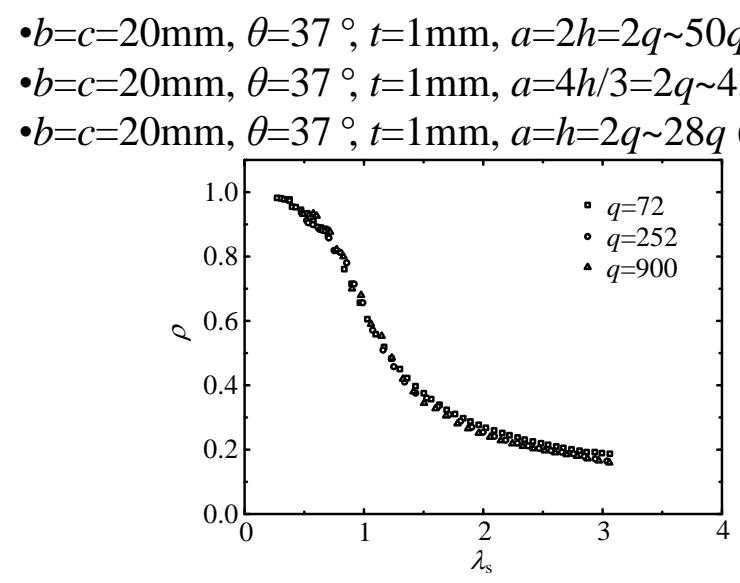

(a) Influence of different corrugated configurations

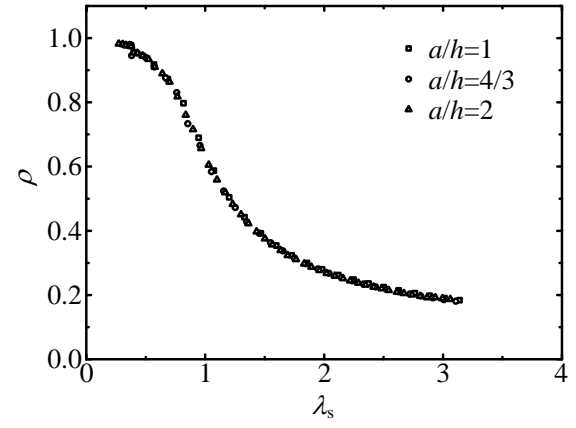

(b) Influence of different shear span ratios

Fig. 6 Influence of corrugated configuration and shear span ratio on the - relationship

It can be clearly seen from Fig. 6 that the - s relationship is unrelated to the corrugated configuration and shear span ratio. As a result, it is reasonable to select a basic example with constant parameters as $b=c=20 \mathrm{~mm},=37^{\circ}, t=1 \mathrm{~mm}$ and $a=2 h=2 q \sim 50 q$ to represent the results of other examples with different values of parameters to investigate the influence of the initial geometric imperfections on the shear strength of webs.

Fig. 7 shows the numerical results of the $-{ }_{s}$ relationship of webs with different initial geometric imperfections of $h / 1000, h / 500$ and $h / 250$. The obtained - s relationship gives the following characteristics:

(1) decreases slowly when ${ }_{\mathrm{s}}$ increases from 0 to about 0.75 ;

(2) decreases fast when ${ }_{\mathrm{s}}$ increases from about 0.75 to about 2.30;

(3) The decrease of $\rho$ tends to slow down when ${ }_{\mathrm{s}}$ is larger than about 2.30;

(4) is insensitive to initial geometric imperfections when $\mathrm{s}_{\mathrm{s}}>2.30$ due to the membrane effect, which makes the loading capacity of webs increasing after shear buckling. Therefore, the actual shear strength of webs considering post-buckling strength is larger than that given by Euler elastic stability curve when ${ }_{\mathrm{s}}>2.30$.

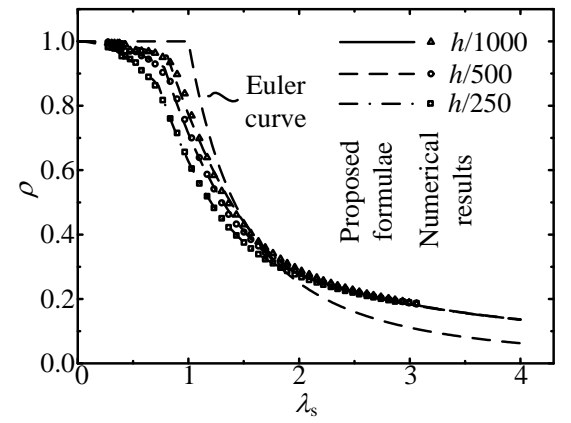

Fig. 7 Numerical and formula results of the $-{ }_{s}$ relationship for different initial geometric imperfections

When s tends to be zero, should tend to be 1 due to the extreme small web height and correspondingly the extreme small value of the initial geometric imperfections. In the other hand, when ${ }_{\mathrm{s}}$ tends to be infinite, should tend to be 0 more slowly than that given by Euler stability curve due to the membrane effect of the thin plate. The proposed formulae of - ${ }_{s}$ relationship for different values of initial geometric imperfections meeting the above two requirements can be derived based on the numerical results as the following equations. 
For the case with the initial geometric imperfection of $h / 1000$ :

$$
\left\{\begin{array}{lr}
1-0.0687 \lambda_{\mathrm{s}}^{2} & \lambda_{\mathrm{s}} \leq 0.81 \\
-0.0535 \lambda_{\mathrm{s}}^{3}+0.5878 \lambda_{\mathrm{s}}^{2}-1.8851 \lambda_{\mathrm{s}}+2.1244 & 0.81<\lambda_{\mathrm{s}} \leq 2.25 \\
\frac{1}{0.05+1.70 \lambda_{\mathrm{s}}+0.03 \lambda_{\mathrm{s}}^{2}} & \lambda_{\mathrm{s}}>2.25
\end{array}\right.
$$

For the case with the initial geometric imperfection of $h / 500$ :

$$
\left\{\begin{array}{lr}
1-0.1320 \lambda_{\mathrm{s}}^{2} & \lambda_{\mathrm{s}} \leq 0.782 \\
-0.1121 \lambda_{\mathrm{s}}^{3}+0.8417 \lambda_{\mathrm{s}}^{2}-2.1764 \lambda_{\mathrm{s}}+2.1604 & 0.782<\lambda_{\mathrm{s}} \leq 2.26 \\
\frac{1}{0.07+1.70 \lambda_{\mathrm{s}}+0.03 \lambda_{\mathrm{s}}^{2}} & \lambda_{\mathrm{s}}>2.26
\end{array}\right.
$$

For the case with the initial geometric imperfection of $h / 250$ :

$$
\left\{\begin{array}{lr}
1-0.2588 \lambda_{\mathrm{s}}^{2} & \lambda_{\mathrm{s}} \leq 0.73 \\
-0.1417 \lambda_{\mathrm{s}}^{3}+0.9349 \lambda_{\mathrm{s}}^{2}-2.1659 \lambda_{\mathrm{s}}+2 & 0.73<\lambda_{\mathrm{s}} \leq 2.30 \\
\frac{1}{0.10+1.70 \lambda_{\mathrm{s}}+0.03 \lambda_{\mathrm{s}}^{2}} & \lambda_{\mathrm{s}}>2.30
\end{array}\right.
$$

Many tests on the shear behavior of H-shape steel girders with trapezoidal corrugated webs have been conducted. Test results provided by Linder and Aschinger ${ }^{[2]}$, Smith $^{[3]}$, Hamilton ${ }^{[3]}$, Peil ${ }^{[18]}$, Lee et al. ${ }^{[19]}$, Gil et al. ${ }^{[20]}$, Driver et al. ${ }^{[5]}$ and Moon et al. ${ }^{[7]}$ can be used for determining the prediction formula of shear strength. The test results of specimens with reasonable parameters for the actual practice as $a / h>1,0.83 \leq b / c \leq 1.20$ and $\geq 22^{\circ}$ are selected and discussed here. Because of good correlation with experimental results, Eq. (14) is appropriate to be selected as the prediction formula of shear strength of trapezoidal corrugated steel webs, as plotted in Fig. 8.

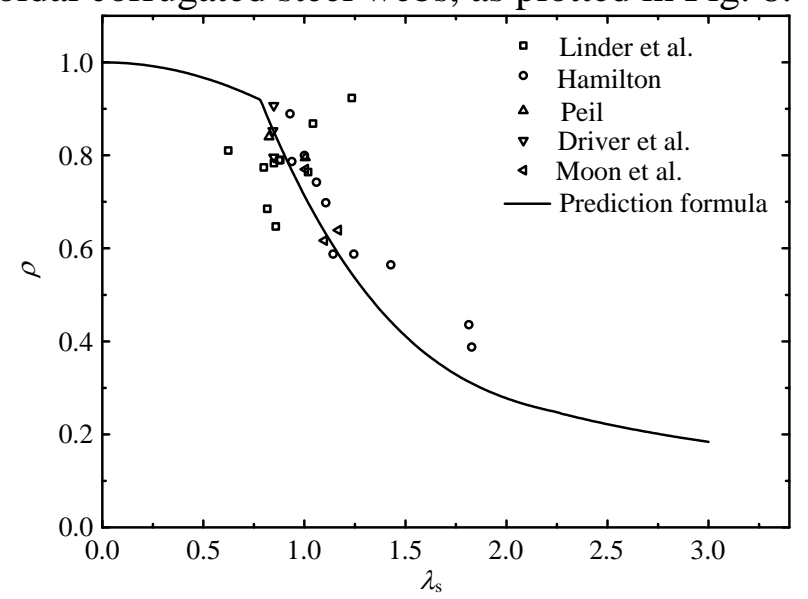

Fig. 8 Determination of the proposed prediction formula through experimental results

\section{Conclusions}

(1) A finite element model is built as the tool for analyzing the shear behavior of trapezoidal corrugated steel webs.

(2) Extensive parametric studies based on the linear elastic buckling analysis are conducted. Based on the previous studies, an appropriate formula is selected to calculate the elastic shear buckling strength of trapezoidal corrugated steel webs. 
(3) The nonlinear buckling analysis is conducted to intensively investigate the shear strength associated with initial geometric imperfections, and the prediction formula of the shear strength is proposed. Good agreements can be observed between the results calculated using the proposed prediction formula in this paper and the experimental results.

\section{References}

[1] Easley J T, McFarland D E. Buckling of light-gage corrugated metal shear diaphragms. ASCE J Struct Div 1969;95(12):1497-516.

[2] Linder J, Aschinger R. Grenzschubtragfähigkeit von I-trägern mit trapezförmig profilierten Stegen. Stahlbau 1988;57(12):377-80.

[3] Elgaaly M, Hamilton R W, Seshadri A. Shear strength of beam with corrugated webs. ASCE J Struct Eng 1996;122(4):390-8.

[4] Sayed-Ahmed E Y. Behavior of steel and (or) composite girders with corrugated steel webs. Can J Civ Eng 2001;28:656-72.

[5] Driver R G, Abbas H H, Sause R. Shear behavior of corrugated web bridge girders. ASCE J Struct Eng 2006;132(2):195-203.

[6] Yi J W, Gil H, Youm H, Lee H E. Interactive shear buckling of trapezoidally corrugated steel webs. Eng Struct 2008;30:1659-66.

[7] Moon J, Yi J W, Choi B H, LeeH E. Shear strength and design of trapezoidally corrugated steel webs. J Const Steel Res 2009;65:1198-205.

[8] Sause R, Braxtan T R. Shear strength of trapezoidal corrugated steel webs. J Const Steel Res 2011;67:223-36.

[9] Luo R, Edlund B. Shear capacity of plate girders with trapezoidally corrugated webs. Thin-Walled Struct 1996;26(1):19-44.

[10]Elgally M, Seshadir A. Depicting the behavior of girders with corrugated webs up to failure using non-linear finite element analysis. Adv Eng Softw 1998; 29(3-6): 195-208.

[11] Ibrahim S A, El-Dakhakhni W W, Elgaaly M. Fatigue of corrugated-web plate girders: analytical study. ASCE J Struct Eng 2006;132(9):1381-92.

[12] Moon J, Yi J W, Choi B H, Lee H E. Lateral-torsional buckling of I-girder with corrugated webs under uniform bending. Thin-Walled Struct 2009;47:21-30.

[13] Galambos T V. Guide to stability design criteria for metal structures. New York: John Wiley \& Sons Inc.; 1998.

[14] Nie J G, Tang L. Global shear buckling of corrugated steel plates with edges elastically restrained against rotation. Eng Mech 2008;25(3):1-7 (in Chinese).

[15]Bergfelt A, Leiva L. Shear buckling of trapezoidally corrugated girder webs. Report Part 2, Pibl.SS4:2. Sweden: Chalmers University of Technology; 1984.

[16] Abbas H H, Sause R, Driver R G. Shear strength and stability of high performance steel corrugated web girders. Structural Stability Research Council Annual Technical Session. SSRC Conference, Seattle; 2002. p. 361-87.

[17] Hiroshi S, Hiroyuki I, Yohiaki I, Koichi K. Flexural shear behavior of composite bridge girder with corrugated steel webs around middle support. JSEC J 2003;724(I-62): 49-67.

[18]Peil U. Statische versuche an trapezstegträgern untersuchung der querkraftbeanspruchbarkeit. Braunschweig: Institut für Stahlbau; 1998 [Germany: Technischen Universität Braunschweig]. 
[19]Lee J, Lee S, Gil H, Lee H E. Shear buckling strength of trapezoidally corrugated steel webs for bridges. Proceeding of the 7th Korea-Japan Joint Seminar on Steel Bridges; 2003. p. 329-39.

[20] Gil H, Lee S, Lee J, Lee H E. Shear buckling strength of trapezoidally corrugated steel webs for bridges. J Transp Res Board 2005;CD11-S:473-80. 